\title{
Acute effect of inhaled bradykinin on tracheobronchial clearance in normal humans
}

Riccardo Polosa, Amir Hasani, Demetri Pavia, John E Agnew, Christopher K Lai, Stewart W Clarke, Stephen T Holgate

\begin{abstract}
Background Bradykinin, a nonapeptide that contributes as a mediator to the pathogenesis of asthma, may affect lung mucociliary clearance, as it has been shown to be a potent secretagogue in canine airways and in human nasal mucosa in vivo. To evaluate this possibility the effect of inhaled bradykinin on mucociliary clearance has been studied in 10 healthy volunteers.

Methods Subjects attended the laboratory on two occasions to take part in tracheobronchial clearance studies using a non-invasive radioisotopic technique. Inhalation of radioaerosol was followed 30 minutes later by inhalation of either bradykinin $(8 \mathrm{mg} / \mathrm{ml})$ or vehicle placebo in a randomised, double blind fashion. After each inhalation the number of coughs was recorded. Whole lung radioactivity was measured every half hour for six hours with two collimated scintillation counters, and a tracheobronchial clearance curve was plotted for each subject on each occasion.
\end{abstract}

Results Mucociliary clearance, expressed as the area under the tracheobronchial radioaerosol retention curve calculated for the first six hours $\left(A \cup C_{0-6 h}\right)$, was greater in nine out of 10 subjects after inhalation of bradykinin than after placebo. The median values (range) for $A U C_{0-6 h}$ were significantly reduced from $126 \%(78-232 \%) / h$ with placebo to $87 \%(51-133 \%) / h$ with bradykinin.

Immunopharmacology Group, Medicine 1, Southampton General Hospital, Southampton SO9 4XY

R Polosa

C K Lai

S T Holgate

Department of Thoracic Medicine, Royal Free Hospital and School of Medicine, London NW3 2QG A Hasani

D Pavia

J E Agnew

$S$ W Clarke

Reprint requests to: Dr R Polosa

Received 3 February 1992 Returned to authors 10 April 1992 Revised version received 26 May 1992 Accepted 28 May 1992 accelerates tracheobronchial clearance in normal human airways.

(Thorax 1992;47:952-956)

Bradykinin is a nonapeptide that may be an important mediator in the pathogenesis of airway inflammation by interacting with specific receptors, mainly of the $B_{2}$ type..$^{1-3}$ The observation that kinin like activity is recovered in increased amounts from lavage fluid following provocation by allergen of the nasal ${ }^{4}$ and bronchial mucosa ${ }^{5}$ of atopic subjects indicates that this pathway is activated in human allergic disease. Inhaled bradykinin elicits many of the features of asthma, including bronchoconstriction, ${ }^{6-8}$ cough, ${ }^{7}$ plasma exudation, ${ }^{9}{ }^{10}$ and mucus secretion. $^{11}$

The impairment of mucociliary function, which has been recently found in patients with both symptomatic and asymptomatic asthma, ${ }^{1213}$ may be related to local release of chemical mediators of anaphylaxis, including bradykinin. In support of this, it has been reported that the allergen provoked early asthmatic reaction is accompanied by a decrease in tracheal mucus transport in asthmatic patients, which could be reversed by pretreatment with sodium cromoglycate, ${ }^{14}{ }^{15}$ a drug that has a potent inhibitory activity on bradykinin responses in the airways. ${ }^{7}$

Animal and in vitro studies suggest that bradykinin may have various effects on different components of the mucociliary transport system. Bradykinin may be directly responsible for the impaired mucociliary clearance in asthma as it has been shown to be a potent mucus secretagogue in canine airways in vivo ${ }^{11}$ and in human nasal mucosa in vitro. ${ }^{16} \mathrm{It}$ also stimulates chloride secretion by canine airway epithelial cells, ${ }^{17}$ leading to an increase in the water content within the periciliary fluid. Altered mucus transport may result not only from abnormalities of the rheological properties of airway secretions but also from impairment of ciliary function. Recently Tamaoki et $a l^{18}$ have shown that bradykinin stimulates ciliary motility in isolated rabbit tracheal epithelium. From these studies an alteration in mucociliary clearance by bradykinin could be predicted.

To our knowledge the effect of bradykinin on bronchial mucociliary clearance in man has not been previously studied. Owing to the complexity of studying the mucociliary clearance response to inhaled bradykinin in asthmatic subjects because of its potent bronchoconstrictor effect, ${ }^{6-8}$ we decided to investigate the effect of inhaled bradykinin on mucociliary clearance using a radioaerosol technique in a group of healthy volunteers.
SUBJECTS

Ten healthy subjects (eight of them male), ranging in age from 19 to 53 years, with no history of respiratory disease and with baseline values of forced expiratory volume in one second $\left(\mathrm{FEV}_{1}\right)$ above $80 \%$ of their maximum predicted values, took part in the study (table 1). Seven subjects (subjects $1,4,5,7,8,9$, and 10) were atopic, as defined by positive responses to skin prick tests (weals over $2 \mathrm{~mm}$ in diameter) with two or more common aeroallergens: house dust, Dermatophagoides pteronyssinus, $D$ farinae, mixed grass pollen, cat fur, dog hair (Bencard, Brentford, Middlesex). Two subjects (subjects 8 and 9) were smokers. Smoking was not allowed for at least 12 hours 
Table 1 Area under the time-course curve $\left(A U C_{0-6 h}, \% . h\right)$ and $95 \%$ tracheobronchial clearance time (95\% TBCT, min) on the placebo and the bradykinin study days

\begin{tabular}{|c|c|c|c|c|c|c|c|}
\hline \multirow[b]{2}{*}{ Subject No } & \multirow[b]{2}{*}{ Sex } & \multirow[b]{2}{*}{ Age (y) } & \multirow[b]{2}{*}{$F E V_{1}(\%$ pred $)$} & \multicolumn{2}{|c|}{ Placebo study day } & \multicolumn{2}{|c|}{ Bradykinin study day } \\
\hline & & & & $A U C_{0-6 h}$ & $\begin{array}{l}95 \% T B C T \\
(\min )\end{array}$ & $A U C_{0-6 h}$ & $\begin{array}{l}95 \% T B C T \\
\text { (min) }\end{array}$ \\
\hline $\begin{array}{r}1 \\
2 \\
3 \\
4 \\
5 \\
6 \\
7 \\
8 \\
9 \\
10\end{array}$ & $\begin{array}{l}M \\
M \\
F \\
M \\
M \\
M \\
M \\
F \\
M \\
M\end{array}$ & $\begin{array}{l}19 \\
23 \\
53 \\
34 \\
27 \\
43 \\
25 \\
20 \\
28 \\
22\end{array}$ & $\begin{array}{r}99 \\
94 \\
101 \\
78 \\
118 \\
89 \\
91 \\
105 \\
87 \\
86\end{array}$ & $\begin{array}{r}232 \\
123 \\
148 \\
78 \\
97 \\
175 \\
129 \\
83 \\
104 \\
152\end{array}$ & $\begin{array}{l}348 \\
310 \\
240 \\
168 \\
175 \\
360 \\
156 \\
115 \\
180 \\
266\end{array}$ & $\begin{array}{r}93 \\
80 \\
133 \\
69 \\
74 \\
109 \\
128 \\
51 \\
76 \\
109\end{array}$ & $\begin{array}{r}124 \\
85 \\
150 \\
78 \\
82 \\
115 \\
160 \\
72 \\
86 \\
198\end{array}$ \\
\hline \multicolumn{2}{|c|}{$\begin{array}{l}\text { Mean or median } \\
\text { SE or range }\end{array}$} & $\begin{array}{r}29 \cdot 4^{\star} \\
3 \cdot 5^{\star}\end{array}$ & $\begin{array}{r}94 \cdot 8^{\star} \\
3 \cdot 6^{\star}\end{array}$ & $\begin{array}{l}126 \\
78-232\end{array}$ & $\begin{array}{l}210 \\
115-360\end{array}$ & $\begin{array}{l}87 \\
51-133\end{array}$ & $\begin{array}{l}101 \\
72-198\end{array}$ \\
\hline
\end{tabular}

$\star$ Mean (SE).

before radioaerosol inhalation or in the subsequent 24 hours' observation period. They took no medication and were free from respiratory tract infections for at least four weeks before and throughout the investigation. Subjects were allowed a light breakfast on the day of the study but could not have caffeine containing substances for the previous 12 hours. The study was approved by the Royal Free Hospital's ethical subcommittee and written informed consent was obtained from each subject.

\section{MEASUREMENTS}

Airways function was measured both as the $\mathrm{FEV}_{1}$ and forced vital capacity (FVC)-by dry bellows spirometer (Vitalograph, Buckingham)_and as the peak expiratory flow (PEF)by peak flow meter (Wright, London)-10-20 minutes before each radioaerosol inhalation. The highest value of three technically acceptable readings was recorded and all values were corrected to body temperature and ambient pressure.

Tracheobronchial clearance was measured by a non-invasive radioisotopic method. ${ }^{19}$ Polystyrene particles $5 \mu \mathrm{m}$ in diameter were firmly tagged with the gamma emitting radionuclide technetium-99m ( $t_{1} 6$ hours) and inhaled via a mouthpiece under strictly controlled conditions. The initial topographical distribution of the radioaerosol within the lungs was monitored with a gamma camera (International General Electric, Berkshire), linked to a computer (Nodecrest, Byfleet, Surrey). Posterior views were obtained to derive a penetration index for the ${ }^{99 \mathrm{~m}} \mathrm{~T}$ c labelled particles (ratio of counts recorded over the peripheral lung to those recorded over central lung). ${ }^{20}$ This index estimates the degree of penetration into the lungs of this radioaerosol relative to that of krypton gas, ${ }^{81 \mathrm{~m}} \mathrm{Kr}\left(t_{\frac{1}{2}} 13\right.$ seconds), which was subsequently inhaled.

Radioaerosol clearance was monitored with two suitably collimated scintillation counters, axially opposed anteroposteriorly over the mid sternum. An immediate radioaerosol count was made to ascertain the initial lung burden. Thereafter counts were made at half hourly intervals for six hours and a final one at 24 hours to estimate radioaerosol deposition on non-ciliated airways ("alveolar deposition"). To overcome unavoidable differences in the amount of radioactivity initially measured in the lung, all counts were expressed as a percentage of the initial count after correction for the natural decay of the radioisotope and background radioactivity. Alveolar deposition for each subject was expressed as the percentage of the initial lung activity remaining in the lungs at 24 hours and was subtracted from all readings of the whole lung clearance curve to give a tracheobronchial clearance curve. Throughout the first six hours after radioaerosol inhalation all coughs were recorded.

BRADYKININ ADMINISTRATION

On each occasion bradykinin triacetic acid (Nova Biochem Ltd, Nottingham) was freshly prepared in $10 \%$ ethanol in normal saline to produce $3 \mathrm{ml}$ of solution containing $24 \mathrm{mg}$. To avoid loss of bradykinin through adherence to plastic surfaces and oxidation, the solution was kept stored at $4^{\circ} \mathrm{C}$ before use and administered within 20 minutes of reconstitution. The control vehicle solution (placebo) consisted of the $10 \%$ ethanol-saline diluent used for dissolving the bradykinin. Both the placebo and the bradykinin solutions were administered as aerosols generated from a starting volume of 3 $\mathrm{ml}$ in a disposable Inspiron Mini-neb nebuliser (CR Bard International, Sunderland) connected to a dosimeter driven by compressed air at a pressure of $138 \mathrm{kPa}\left(25 \mathrm{lb} / \mathrm{in}^{2}\right)$. The dosimeter setting was adjusted so that this procedure generated $80-100 \mu \mathrm{l}$ of an aerosol with a mass median particle diameter of $4.7 \mu \mathrm{m}$ at the mouth. ${ }^{21}$ Subjects, wearing nose clips, were instructed to take five consecutive breaths from end tidal volume to total lung capacity via a mouthpiece as described by Chai et al. ${ }^{22}$

\section{STUDY DESIGN}

Each subject attended the laboratory on two occasions separated by at least two weeks to undertake tracheobronchial clearance studies. Before radioaerosol inhalation baseline values of $\mathrm{FEV}_{1}, \mathrm{FVC}$, and PEF were obtained. On each occasion subjects inhaled either bradykinin $(8 \mathrm{mg} / \mathrm{ml})$ or vehicle placebo 30 minutes after inhalation of the radioaerosol in a 
Table 2 Baseline spirometric values, inspiratory flow rates, penetration indices, and alveolar deposition on the two study days $\star$

\begin{tabular}{lcc}
\hline & Placebo & Bradykinin \\
\hline FEV $_{1}(1) \dagger$ & $4 \cdot 1(0 \cdot 3)$ & $4 \cdot 0(0 \cdot 3)$ \\
FVC $(1) \dagger$ & $4 \cdot 7(0 \cdot 4)$ & $4 \cdot 7(0 \cdot 3)$ \\
PEF $(1 /$ min $) \dagger$ & $576(25)$ & $562(26)$ \\
Alveolar deposition $(\%) \ddagger$ & $49(32-72)$ & $55(23-70)$ \\
Inspiratory flow rate $(1 / \min ) \ddagger$ & $41 \cdot 9(28 \cdot 9-47 \cdot 1)$ & $38 \cdot 6(26 \cdot 2-47 \cdot 5)$ \\
Penetration index (units) $\ddagger$ & $0 \cdot 62(0 \cdot 48-0 \cdot 78)$ & $0 \cdot 71(0 \cdot 41-0 \cdot 80)$ \\
\hline
\end{tabular}

^All differences are non-significant.

$\dagger$ Mean (SE).

†Median (range).

FVC-forced vital capacity; PEF-peak expiratory flow.

randomised and double blind manner. The inhalation procedure with both bradykinin and vehicle placebo was repeated on a further three occasions at half hourly intervals. After each inhalation of bradykinin and placebo solutions, the number of coughs was counted and recorded by an independent observer. Although subjects were not told which was the active solution, the pharyngeal irritation with bradykinin made it difficult to maintain blindness. The investigators responsible for analysing the data (AH and DP) were not, however, aware of the subjective sensations of the subjects studied, who were blind to the rationale of the study. Regular whole lung counts were obtained as described above and a tracheobronchial clearance curve was plotted for each subject on each occasion.

\section{DATA ANALYSIS}

All figures are means and standard errors unless otherwise stated and $\mathrm{p}<0.05$ was accepted as the level of significance. Baseline values of $\mathrm{FEV}_{1}, \mathrm{FVC}$, and PEF on the two study days were compared by paired Student's $t$ test. Topographical distributions of the radioaerosol within the lungs on the two study days were compared by the Wilcoxon signed rank test on penetration indices, alveolar deposition, and inspiratory flow rates. The Wilcoxon signed rank test was also used to compare the number of coughs after bradykinin and placebo. The relation between the number of coughs after bradykinin inhalations and the degree of acceleration of mucociliary transport was investigated by the Kendall correlation test. To quantify tracheobronchial clearance, areas under the curves for tracheobronchial retention of the ${ }^{99 \mathrm{~m}} \mathrm{Tc}$ polystyrene particles (AUC) were calculated by trapezoid integration between time points 0 and 6 hours $\left(\mathrm{AUC}_{0-6 \mathrm{~h}}\right)$ and between time points 0 and 3 hours $\left(\mathrm{AUC}_{0-3 \mathrm{~h}}\right)$. The efficiency of the mucociliary transport in the subjects studied was also expressed as $95 \%$ tracheobronchial clearance time, which represents the time needed to clear $95 \%$ of the initial radioaerosol deposition within the lung. The values of $\mathrm{AUC}_{0-6 \mathrm{~h}}$ and $\mathrm{AUC}_{0-3 \mathrm{~h}}$ and the $95 \%$ tracheobronchial clearance time for the two study days were compared by Wilcoxon signed rank test.

\section{Results}

There were no significant differences in the baseline spirometric values between the two study days (table 2). Similarly, inspiratory flow rates, penetration indices, and alveolar depositions were not significantly different on bradykinin and placebo study days (table 2 ).

All subjects noticed pharyngeal irritation after inhaling bradykinin; this was most noticeable with the first inhalation but rapidly diminished during subsequent inhalations. In addition, four subjects (subjects $7,8,9,10$ ) had a dry cough with bradykinin. Although the median (range) number of coughs recorded after bradykinin inhalations $(2.0(0-18))$ was significantly higher than the $0.5(0-2)$ after placebo ( $\mathrm{p}<0.05)$, no significant correlation was found between acceleration of tracheobronchial clearance and number of coughs recorded throughout the first six hours after radioaerosol inhalation.

Mucociliary clearance, expressed as $\mathrm{AUC}_{0-6 \mathrm{~h}}$ and $\mathrm{AUC}_{0-3 \mathrm{~h}}$, was greater in nine out of 10 subjects after inhalation of bradykinin than after placebo (figure). The medians (range) for $\mathrm{AUC}_{0-6 \mathrm{~h}}$ and $\mathrm{AUC}_{0-3 \mathrm{~h}}$ were reduced from 126 (78-232) to $87(51-133) \% . h(p<0.001)$ after placebo and from $121(78-192)$ to 86 (51$133) \% . h(p<0.01)$ after bradykinin (figure,


Hours after inhalation of radioaerosol

Figure Individual tracheobronchial retention curves for 10 normal subjects after inhalations of bradykinin (solid circles) and vehicle placebo (open squares). $\uparrow \uparrow \uparrow \uparrow$ Bradykinin or placebo inhalations. 
table 1). Inhaled bradykinin reduced $95 \%$ tracheobronchial clearance time in all but one subject (No 7), the median (range) $95 \%$ tracheobronchial clearance time decreasing from $210(115-360)$ to $101(72-198)$ minutes after administration of placebo and bradykinin respectively (table 1 ).

\section{Discussion}

In the present study we have shown that repeated inhalations of bradykinin greatly enhance tracheobronchial clearance in normal human airways. Because the deposition pattern of the inhaled radioaerosol was the same on the two study days, as clearly shown by the reproducibility of penetration indices and alveolar deposition values, the speeding of mucociliary clearance is likely to indicate the true result of bradykinin stimulation and not different deposition of the radioaerosol on the two study days. With the nebulisation procedure used, about $10 \%$ of the dose administered to the mouth $(80 \mu \mathrm{g})$ would be delivered to the airways of our subjects. This dose produces a concentration of the same magnitude as the concentration of kinin like activity in bronchoalveolar lavage fluid from subjects with asthma, ${ }^{523}$ indicating that bradykinin released into the airways as a component of the inflammatory response in asthma might serve to influence the mucociliary transport.

The tracheobronchial retention curves in our subjects closely resemble those previously reported in normal human subjects. ${ }^{24}$ The low concentration of alcohol used in the vehicle solution is therefore unlikely to have altered clearance as such. The technique of measuring tracheobronchial clearance used in this study is highly repeatable, with an intersubject coefficient of variation for healthy non-smokers of $13 \%$, the intrasubject coefficient being half of the intersubject coefficient. ${ }^{24}$

In view of the profound effects on mucosal inflammation ${ }^{325}$ and mucus hypersecretion ${ }^{1626}$ reported in several studies performed on animal models in vitro and in vivo after exposure to bradykinin, it is not surprising that this nonapeptide has a potent action on mucociliary clearance in human airways. Bradykinin may stimulate mucociliary clearance by several mechanisms. One possibility is that this and related peptides alter the rheological properties of tracheobronchial secretions, rendering them less viscous and more easily transportable. Leikauf $e t$ al ${ }^{17}$ have shown that in canine trachea bradykinin may affect ion transport and water flux across the epithelium. Such water flux redistribution may in turn alter the rheological properties of the periciliary layer. In addition, topical application of bradykinin to mucosal surfaces causes vasodilation $^{3}$ and plasma. extravasation. ${ }^{327}$ More recently we have shown that topical application of bradykinin to human airway mucosa provokes plasma leakage into the nasal fluid, ${ }^{10}$ thus confirming results of animal studies. Possibly therefore an increase in plasma exudate at the level of the bronchial mucosa modifies the rheological properties of the tracheobronchial secretions. Bradykinin could also accelerate mucociliary clearance by its effect on mucus secretion. In anaesthetised dogs bradykinin stimulates tracheal gland secretion. ${ }^{11}$ Moreover, Baraniuk et al ${ }^{16}$ have shown that human nasal fragments release increased amounts of secretory products (glycoconjugate) in response to bradykinin. A similar finding has been reported for explants of ferret trachea. ${ }^{16}$

Efficient mucociliary clearance depends not only on the composition and consistency of the periciliary layer and the amount and viscoelastic properties of the epiphase but also on the beat frequency and coordination of the cilia. ${ }^{28}$ Lindberg and Mercke ${ }^{29}$ found that bradykinin increases mucociliary activity in the rabbit maxillary sinus, probably through activation of neural reflexes. Recent evidence from in vitro studies confirm the potent ciliostimulatory action of bradykinin in the rabbit ${ }^{18}$ and dog trachea. ${ }^{30}$ In these preparations the authors could not elicit any failure of ciliary coordination. The effect of bradykinin on ciliary motility in human airway epithelium, however, remains to be investigated.

Although our results suggest that bradykinin may have a direct effect on mucociliary clearance, its ability to release various prostanoids in the guinea pig in vitro ${ }^{311}$ and humans in vivo $^{32}$ and to degranulate mast cells in vitro ${ }^{33} 34$ may enable it to influence this airway function by modulating the generation of chemical mediators within the airways. Prostaglandins, leukotrienes, and histamine accelerate the beating frequency of cilia in airway epithelial cells in vitro. ${ }^{356}$ In addition, the effect of inhaled histamine on bronchial mucociliary clearance investigated with a radioaerosol technique in six healthy subjects has clearly shown an enhancing effect of the same magnitude as that seen in our investigation. ${ }^{37}$ At least in humans in vivo, however, the contribution of intermediate inflammatory products to the overall response to bradykinin stimulation seems to be small. For example, the mode of action of bradykinin in provoking bronchoconstriction in asthmatic subjects does not seem to depend on the release of histamine ${ }^{38}$ or prostanoids. ${ }^{78}$ Similarly, bradykinin induced weal and flare in humans are not altered by pretreatment with an antihistamine or cyclooxygenase inhibitor. ${ }^{39}$ That bradykinin may have indirect effects on mucociliary clearance is a possibility that remains to be investigated.

As healthy volunteers were studied in the present investigation, it is difficult to extrapolate these data to patients with bronchial asthma, whose clearance rate is already reduced. ${ }^{1213}$ Nevertheless, although the airways response to inhaled bradykinin differs strikingly in asthmatic and non-asthmatic subjects ${ }^{68}$ mucociliary clearance may not differ in the same way. Indeed, histamine, another well known mediator of bronchoconstriction in asthma, when inhaled enhanced the mucociliary transport to a similar degree in healthy volunteers and in asthmatic subjects. ${ }^{37} 40$

Mucociliary clearance has been reported to be slower in subjects with asthma, even during 
clinical remission, than in normal subjects. ${ }^{12-15}$ These findings are at variance with the results of the present study, which show a speeding of the mucociliary clearance by acute exposure to bradykinin, a putative mediator in the pathophysiology of asthma. It has been recently reported, however, that acute exacerbations of asthma sharply accelerated mucociliary transport from baseline in eight asthmatic patients, even though two weeks after an asthma attack their mucociliary clearance was significantly less than the baseline level. ${ }^{41}$ Acute exposure to bradykinin may initially cause a transient increase in mucociliary function, whereas chronic exposure to this kinin may be followed by prolonged depression of mucociliary transport.

Although our findings clearly indicate that inhaled bradykinin stimulates tracheobronchial clearance in normal human airways, further experiments are required to confirm whether it is directly responsible for the impaired mucociliary transport seen in bronchial asthma. Only when suitable antagonists become available will it be possible to establish the importance of this mediator in modulating mucociliary transport.

We thank Dr CI Cordaro for her support and interest.

1 Kunkel GH, Graf K, Niehus J, Baumgarten CR. The role of kinins in pathophysiology of airway disease. In: Godard $\mathrm{Ph}$, Bousquet J, Michel FB, eds. Advances in allergology and clinical immunology. Carnforth, Lancashire: Parthenon, 1992:305-13.

2 Proud D, Baumgarten CR, Naclerio RM, Lichtenstein LM. The role of kinins in human allergic disease. NER Allergy Proc 1986;7:213-8.

3 Regoli D, Barabe J, Pharmacology of bradykinin and related peptides. Pharmacol Rev 1980;31:1-46.

4 Proud D, Togias A, Naclerio RM, Crush SA, Norman PS Lichtenstein LM. Kinins are generated in vivo following nasal airway challenge of allergic individuals with allergen. $J$ Clin Invest 1983;72:1678-85.

5 Liu MC, Hubbard WC, Proud D, Stealey BA, Galli SJ, Kagey-Sobotka A, et al. Immediate and late inflammatory responses to ragweed antigen challenge of the peripheral airways in allergic asthmatics. Am Rev Respir Dis 1991;144:51-8.

6 Simonsson BG, Skoogh BE, Bergh NP, Anderson R, Svedmyr $\mathrm{N}$. In vivo and in vitro effect of bradykinin on bronchial motor tone in normal subjects and in patients bronchial motor tone in normal subjects and in patient

7 Fuller RW, Dixon CMS, Cuss FMC, Barnes PJ. Bradykinin-induced bronchoconstriction in humans. Mode of action. Am Rev Respir Dis 1987;135:176-80

8 Polosa R, Holgate ST. Comparative airway response to inhaled bradykinin, kallidin and [desArg9]-bradykinin in normal and asthmatic subjects. Am Rev Respir Dis 1990;142:1367-71.

9 Haddy FJ, Emerson TE, Scott JB, Daugherty RM. The effect of the kinins on the cardiovascular system. In Brodie BB, Jillett JP, eds. Handbook of experimental pharmacology. Vol 25. Berlin: Springer, 1970:362-84.

10 Rajakulasingam K, Polosa R, Lau LCK, Holgate ST, Howarth PH. The nasal effects of bradykinin and capsaicin: role of "C" sensory nerve fibres. J Appl Physiol 1992;72:1418-24.

11 Davis B, Roberts AM, Coleridge HM, Coleridge JCG Reflex tracheal gland secretion evoked by stimulation of Reflex tracheal gland secretion evoked by stimulation of
bronchial C-fibres in dogs. J Appl Physiol 1982;51: 985-91.

12 Bateman JRM, Pavia D, Sheahan NF, Agnew JE, Clarke $\mathrm{SW}$. Impaired tracheobronchial clearance in patients with SW. Impaired tracheobronchial clearance in

13 Pavia D, Bateman JRM, Sheahan NF, Agnew JE, Clarke SW. Tracheobronchial mucociliary clearance in asthma: impairment during remission. Thorax 1985;40:171-5.

14 Mezey RJ, Cohn MA, Fernandez RJ, Januszkiewicz AJ,
Wanner A. Mucociliary transport in allergic patients with antigen induced bronchospasm. Am Rev Respir Dis 1978;118:677-84

15 Ahmed T, Greenblatt DW, Birch S, Marchetti B, Wanner A. Abnormal mucociliary transport in allergic patients with antigen induced bronchospasm: role of SRS-A. Am Rev Respir Dis 1981;124:110-4.

16 Baraniuk JN, Lundgren JD, Mizoguchi H, Peden D, Gawin A, Merida $M$, et al. Bradykinin and respiratory mucous membranes: analysis of bradykinin binding site distribumembranes: analysis of bradykinin binding site distribution and secretory responses

17 Leikauf GD, Ueki IF, Nadel JA, Widdicombe JH. Bradykinin stimulates $\mathrm{Cl}$ secretion and prostaglandin $\mathrm{E} 2$ release by canine tracheal epithelium. Am J Physiol 1985;248. F48-55.

18 Tamaoki J, Kobayashi K, Sakai N, Chiyotani A, Kanemura $\mathrm{T}$, Takizawa $\mathrm{T}$. Effect of bradykinin on airway ciliary motility and its modulation by neutral endopeptidase. $A m$ Rev Respir Dis 1989;140:430-35.

19 Pavia D, Bateman JRM, Sheahan NF, Agnew JE, Newman $\mathrm{SP}$, Clarke SW. Techniques for measuring lung mucociliary clearance. Eur J Respir Dis 1980;61(suppl 110):157-77.

20 Agnew JE, Pavia D, Clarke SW. Airway penetration of inhaled radioaerosol: an index to small airway function? Eur J Respir Dis 1981;62:239-55.

21 Lewis RA. Therapeutic aerosols. In: Cummings G, Bonsignore C, eds. Drugs and the lung. London: Plenum, 63-86.

22 Chai H, Farr RS, Froehlich LA, Mathison DA, McLean JA, Rosenthal RR, et al. Standardization of bronchial inhalation challenge procedures. J Allergy Clin Immunol 1975;56:323-7.

23 Christiansen SC, Proud D, Cochrane CG. Detection of tissue kallikrein in the bronchoalveolar lavage fluid of asthmatic subjects. $J$ Clin Invest 1987;75:188-97.

24 Del Donno M, Pavia D, Agnew JE, Lopez-Vidriero MT, Clarke $S W$. Variability and reproducibility in the measurement of tracheobronchial clearance in healthy subjects and patients with different obstructive lung subjects and patients with differe

25 Kowalski ML, Kaliner MA. Neurogenic inflammation, vascular permeability and mast cells. J Immunol 1988; 140:3905-11.

26 Richardson PS, Phipps RJ, Balfre K, Hall RL. The roles of mediators, irritants and allergens in causing mucin secretion from trachea. In: Porter R, Rivers J, O'Connor M, eds. Respiratory tract mucus. Amsterdam: Elsevier, 1978:11-31.

27 Saria A, Lundberg JM, Skofitsch G, Lembeck F. Vascular protein leakage in various tissues induced by substance $P$, capsaicin, bradykinin, serotonin, histamine and by antigen challenge. Naunyn Schiedebergs Arch Pharmacol 1983;324:212-8.

28 Sleigh MA, Blake JR, Liron N. The propulsion of mucus by cilia. Am Rev Respir Dis 1988;137:726-41.

29 Linberg S, Mercke U. Bradykinin accelerates mucociliary activity in rabbit maxillary sinus. Acta Otolaryngol 1986:101:114-21

30 Wong LB, Miller IF, Yeates DB. Regulatory pathways for the stimulation of canine tracheal ciliary beat frequency by bradykinin. J Physiol (Lond) 1990;422:421-31.

31 Rossoni G, Omini C, Vigano T, Mandelli V, Folco GC, Berti F. Bronchoconstriction by histamine and bradykinin in guinea-pigs: relationship to thromboxane A2 generation and the effect of aspirin. Prostaglandins 1980;20:547-57.

32 Barrow SE, Dollery CT, Heavey DJ, Hickling NE, Ritter $\mathrm{JM}$, Vial J. Effect of vasoactive peptides on prostacyclin

33 Johnson AR, Erdos EG. Release of histamine from mast cells by vasoactive peptides. Proc Soc Exp Biol Med by vasoactive pept

34 Ishizaka $\mathrm{T}$, Iwata $M$, Ishizaka $\mathrm{K}$. Release of histamine and arachidonate from mouse mast cells induced by glycosylation-enhancing

35 Wanner A, Maurer D, Abraham WM, Szepfalusi Z, Sielczak $M$. Effect of chemical mediators of anaphylaxis on ciliary function. J Allergy Clin Immunol 1983;72:663-7.

36 Wanner A, Sielczak M, Mella JF, Abraham WM. Ciliary responsiveness in allergic and non-allergic airways. $J A p p l$ Physiol 1986;60:1967-71.

37 Mussatto DJ, Garrard CS, Lourenco RV. The effect of inhaled histamine on human tracheal mucus velocity and bronchial mucociliary clearance. Am Rev Respir Dis 1988;138:775-9.

38 Polosa R, Phillips GD, Lai CKW, Holgate ST. Contribution of histamine and prostanoids to bronchoconstriction provoked by inhaled bradykinin in atopic asthma. Allergy provoked by inhal

39 Crossman DC, Fuller RW. Bradykinin induced wheal and flare is not mediated by histamine release or cyclooxygenflare is not mediated by histamine release or cycloox

40 Garrard CS, Mussatto DJ, Lourenco RV. Lung mucociliary transport in asymptomatic asthma: effects of inhaled transport in asymptomatic asthma: effect
histamine. J Lab Clin Med 1989;113:190-5.

41 Kurashima K, Ogawa H, Ohka T, Fujimura M, Matsuda T Mucociliary transport disturbance after an asthmatic attack. Arerugi 1990;39:631-5. 